Document downloaded from:

http://hdl.handle.net/10251/136407

This paper must be cited as:

Linares-Pellicer, J.; Orta-López Jorge; Izquierdo-Doménech, JJ. (2018). Flipping Game Development. IEEE Computer Graphics and Applications. 38(6):118-124. https://doi.org/10.1109/MCG.2018.2876487

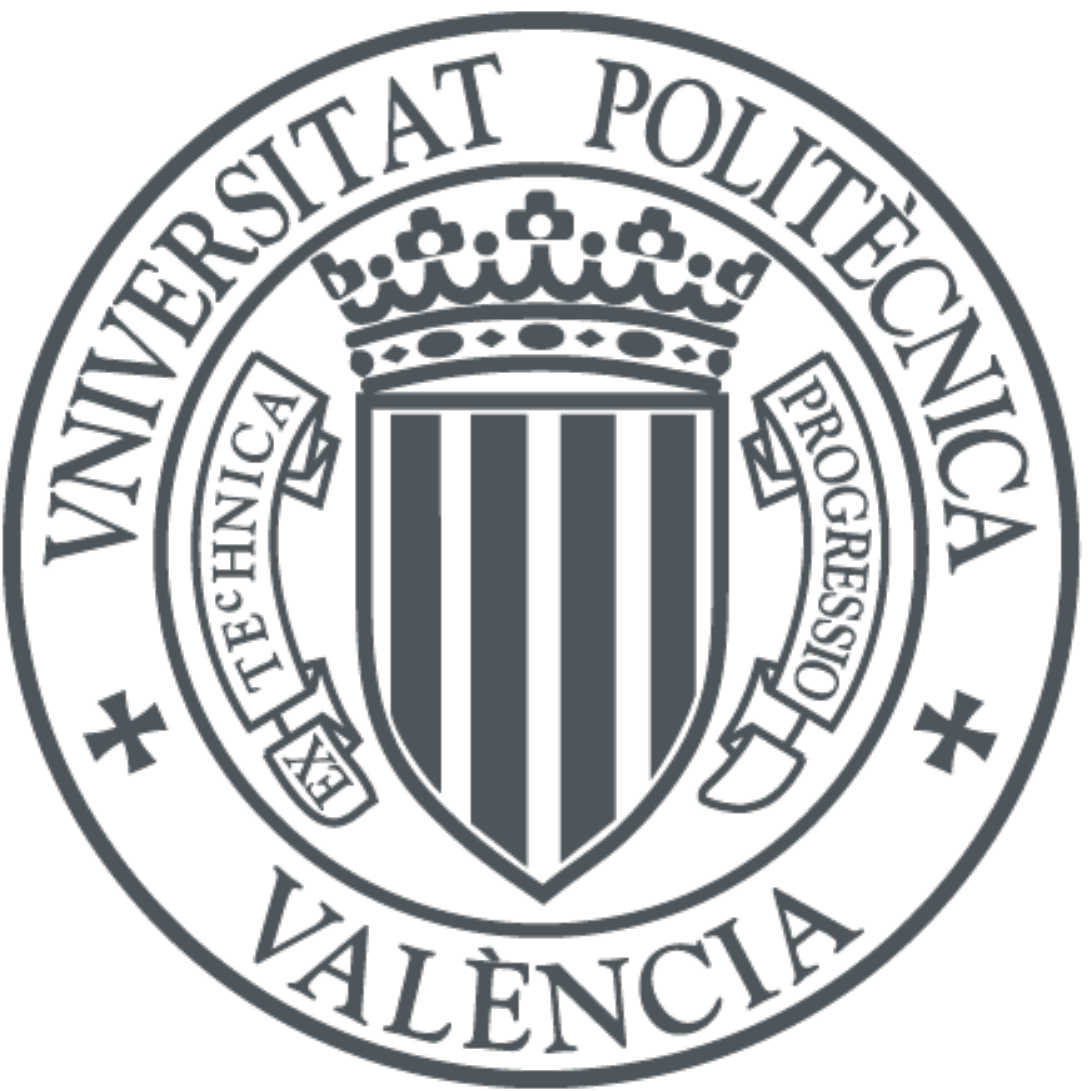

The final publication is available at

https://doi.org/10.1109/MCG.2018.2876487

Copyright Institute of Electrical and Electronics Engineers

Additional Information 


\section{Flipping Game Development}

Jordi Linares-Pellicer Instituto Tecnológico de Informática, Universitat Politècnica de València

Jorge Orta-Lopez

Instituto Tecnológico de Informática, Universitat Politècnica de València

Juan Izquierdo-Domenech Instituto Tecnológico de Informática, Universitat Politècnica de València

\begin{abstract}
This work describes the implementation of a flip teaching alternative in an introductory game development course, using resources from a MOOC (Massive Open On-Line Course). The results proved to achieve better grades and higher satisfaction to previous and similar lecture-based courses.
\end{abstract}

Students nowadays have a profile that is generally different from that of a few years ago. They are accustomed to using the Internet and multimedia material to learn the things they need. They generally do not look at manuals or

technical books, nor do they delve through great quantities of written information. They are much more likely watch videos and tutorials and then learn by doing rather than reading, using software that they instinctively know how to use from the first moment. They do not favour the traditional elements of teaching support if they have an alternative. They expect innovation in their learning process and may lose interest if they are not continually doing things.

\section{FLIP TEACHING AS AN ALTERNATIVE TO TRADITIONAL TEACHING METHODS}

The lack of motivation that is often present in lecture-based teaching methods in students nowadays has led to a situation where flip teaching is being well-received by the current crop of students, including those who are at university. ${ }^{1}$

Classes that are teacher-based lectures do not always meet their expectations. One, two or even three hours following an explanation focusing mainly on theoretical concepts is probably not the most appropriate method of teaching in many contexts. The sense of disconnection is immediate and with this comes the sensation that the student is not spending their time in a productive way.

Turning this situation around is the objective of flip teaching. The students do indeed have to invest time doing out-of-class work but not resolving problems and doing exercises as they do in a more traditional approach. Teachers will be spending time with students at class but not in teacher-based lecture classes that are sometimes less productive.

With the flip teaching approach the students prepare the theoretical concepts in their own time before coming to the classes (pre-class activities). The class should then focus on interaction between teacher and student, concentrating on practical work, exercises, consolidating knowledge, teamwork and student progress evaluation.

The lower levels of learning, in the revised Bloom's taxonomy, that of remembering and understanding, take place outside the classroom, at the student's own pace. In the class, having 
the instructor as a guide, the learning can now involve the higher levels of Bloom's taxonomy, that of applying, analyzing, evaluating and creating. ${ }^{2}$

In this context, videos and multimedia material are a perfect complement to transmit theoretical concepts to current students. Video tutorials are preferred by developers for learning new contents, and text tutorials for looking up "missed" information. ${ }^{3}$ The students can study this material at home and they consult it for as long as is necessary.

When they get together in the classroom, the teacher no longer has to give a lecture-based class, and can devote this time to proposing exercises, tasks and individual or group work, which allows the students to consolidate their theoretical knowledge. Finally, with flip teaching, the teacher can better evaluate the students' progress, analyzing their evolution in each session, and applying continuous evaluation.

Other teaching approaches can co-exist and complement flip teaching such as Project-Based Learning. ${ }^{4}$ In our case the work in the classroom is more based on Problem-Based Learning ${ }^{5}$ and its generalization known as Activity-Led Instruction ${ }^{6}$.

\section{AN INTRODUCTORY COURSE TO GAME PROGRAMMING}

The flip teaching methodology has been applied to an introductory course to game programming which details are given next:

- Introduction to Game Programming is a 4.5 ECTS (45 teaching hours) elective course for undergraduate students in the fourth year, spring semester of our Degree in Computer Engineering. 1 ECTS means generally from 25 to 30 hours of total work. This means that with 45 teaching hours students must complement this work with from 45 to 90 hours at home. What the students will do with these hours is the main change of flip teaching.

- The main contents of the course and its proportions can be summarized as follows: basic concepts about games, genres and history (5\%), a basic introduction to game design concepts and stages (10\%), the Game Design Document (GDD) (5\%), introduction to game engines, their tools and libraries $(10 \%)$, and introduction to game programming using a multiplatform game engine $(70 \%)$.

- Students must finish the course developing their own game and its GDD, elements that will be used for course assessment

- No computer graphics knowledge as prerequisite, only programming knowledge on a OOP language.

Being the main objective of the course the development of a game using a game engine, the free educational license of Unity game engine was selected as one of the several current options.

The methodology in use in this course so far has been quite traditional: lectures explaining theoretical concepts and explanations on how to develop games using the game engine. Students' time at home was most focused on practicing and solving problems with the game engine.

Although the students' results and grades of the course were not bad, we wondered if the use of flip teaching could help students to work on more complex challenges and problems and achieve better and more advanced games in the end. The idea was simple: instead of explaining theoretical concepts and how to develop a game using a game engine at the classroom, use a collection of videos the students can watch before coming to class. In this way, at the classroom we are able to focus on problems and solving specific challenges with the objective to force the students to work on developing games most of the lecturing hours.

\section{MOOCS AS A TOOL FOR LEARNING}

MOOCs, after their consolidation, are a great online education tool and make learning available for anyone at any time. ${ }^{7}$ They are generally made up of videos, multimedia elements, online evaluation tools and other resources that students nowadays are very familiar with. 
Our experiences with MOOCs have led to the preparation of an introductory course on game development with the Unity platform ${ }^{8}$ on the prestigious platform edX ${ }^{9}$. In its different editions it has been studied by more than 15,000 students and the feedback has been extremely positive. Our institution has a long trajectory creating MOOCs (first one in Spanish language, fifth globally) with very good results. ${ }^{10}$

Game programming is one of the fields that is proving interesting for students, and using MOOCs for learning their techniques is challenging. Although the focus has to be mainly practical, it is also important to cover important theoretical concepts which will allow students to have the necessary knowledge to understand the basic elements of real-time graphics and other concepts such as physics engines. It is important to offer a solution that uses a range of resources for the different concepts and learning objectives.

The MOOC videos were prepared following some guidelines derived by an extensive study on edX MOOCs: ${ }^{11}$

- Shorter videos are much more engaging. Engagement drops sharply after 6 minutes.

- Videos that intersperse an instructor's talking head with PowerPoint slides are more engaging than showing only slides.

- Khan-style tablet drawing tutorials are more engaging than PowerPoint slides.

Given the complexity of the course, 5 different types of videos were chosen (see Figure 1), each of which covers different teaching objectives:

- Videos with slides and the presence of the teacher that cover the more general theoretical concepts. This is more similar to a traditional lecture but designed to be brief and to the point. This focus is ideal to explain the characteristics of real time graphics and their challenges, physics engines, collision detection etc.

- Khan-style tablet drawing videos in which the teacher, using a tablet, explains different theoretical concepts in a more interactive way than simply using slides. For example, in Figure 1 (top-right), the concept of frames per second is explained along with delta time in real time animation.

- Screencast videos, in which practical exercises on programming and editing tools are carried out in step-by-step process. Complete slides and code are also available.

- Screencast videos where visualization of the development tools is complemented by the presence of the teacher. This is necessary, for example, when introducing the interaction between the user and mobile devices and their sensors and touch screen.

- Videos of interviews with professionals have also been included, which are probably the best way to help students to become aware of the career opportunities available to them.
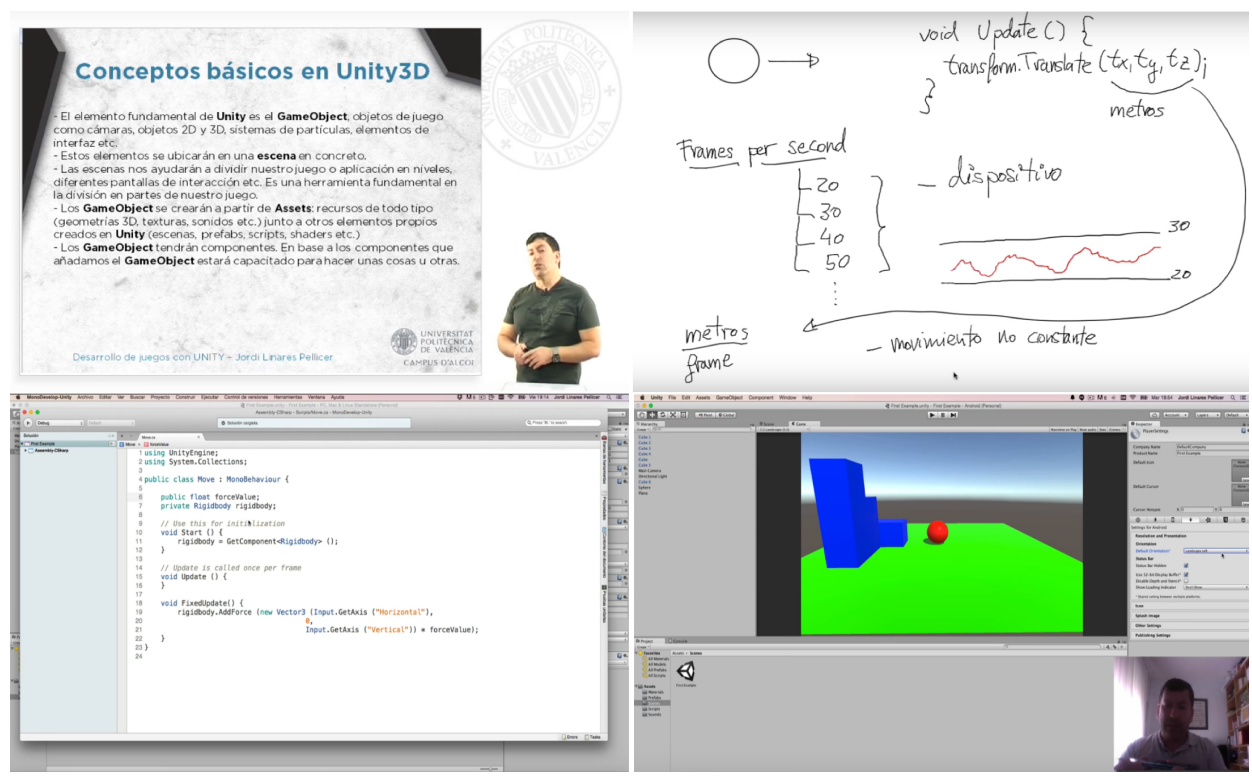
Figure 1. Different videos used: (top-left) slides and traditional explanations; (top-right) pen writing with a tablet; (bottom-left) screencast for practical work; (bottom-right) screen cast combined with images provided by the teacher.

\section{USING A MOOC IN FLIP TEACHING}

Although not compulsory, the teaching materials of the MOOC and its assessment tools make it a perfect set of assets for any flip teaching course.

This is the focus that has been followed in a course in our Computer Engineering Degree. This course has similar objectives as the MOOC: to offer an introduction to game development. The MOOC makes the application of flip teaching much easier:

- A collection of videos and on-line resources allow students to learn the theoretical elements at home (pre-class work).

- Evaluation of theoretical knowledge before each class, as the MOOC has an evaluation tool, by modules, which can be used to determine whether the students have done the required work before the classroom sessions. This is very important in the flip teaching methodology. If students go to classroom without the required knowledge this approach will not work.

- The work in the classroom can be based on adding new features to the exercises presented in the MOOC.

\section{CHANGING TO FLIP TEACHING}

Previous course structure was scheduled to run for 9 weeks, with classroom sessions of 5 hours. Most of these sessions were devoted to traditional lectures focused on theoretical concepts (30\%) and how to develop games with a multiplatform engine (70\%). Only $10-20 \%$ of the total session time was available for workshops and basic exercises. Students were encouraged to solve some more challenging exercises at home (post-class work).

With flip teaching, passive learning activities such as unidirectional lectures are pushed to outside class hours using the MOOC and some additional theoretical topics, and precious class time is spent on active learning activities focused on problem solving and the development of little examples.

The course scheduling with flip teaching has not changed: 9 weeks with classroom sessions of 5 hours. But in this case, most of the time is focused on problem and challenge solving, mainly implementing simple game mechanics and little 2D and 3D games.

The MOOC is divided into 6 modules to be completed over 6 weeks ( 3 hours per week). We have synchronized both activities. The course has been planned in such a way that it leaves the final 3 weeks free of planned content. These final weeks are used for the students to develop their own final game, with the presence and interaction of the teacher.

The MOOC and the course share many of their objectives, although students following the course must be able to develop much more complex examples and a complete final game. Besides, they must know some additional theoretical concepts that are not part of the MOOC.

The routine of each of the 6 weeks synchronized with the MOOC is as follows:

- The students must follow one of the modules of the MOOC at home, and then achieve satisfactory results in its on-line evaluation tool. This evaluation obliges the students to really study the contents of the module before going to class and solve at home some basic exercises (that were the only ones solved at class in the previous approach). This is complemented by some basic theoretical concepts that are not covered by the MOOC. The evaluation of each student is then checked by the teacher at the beginning of the class.

- In the classes, the teacher then summarizes what the students have learned in each module and any additional information provided. 
- The teacher presents a series of exercises and tasks that the students must complete during the classroom session. The idea is that students reinforce what they have learned at home, consolidate understanding of concepts and resolve new tasks. The motto is 'learning by doing'. Based on small examples seen in the MOOC, the students must add new features, resolve new problems, add new logic to the characters in the game, along with new mechanics, etc.

- The presence of the teacher in these sessions is extremely important. The teacher will resolve problems, clarify points of interest, detect errors and offer alternatives. This work is intense but also gratifying for both student and teacher.

- The class ends with an evaluation of the work carried out by the students in this session, so the progress and evolution of the student can be measured.

The student's final grades are 50\% the evaluation of their activities in all the sessions, and the remainder $50 \%$ a final game they have to develop during the last 3 sessions.

The MOOC offers perfect materials for the students to acquire the necessary knowledge before attending the corresponding class with the teacher. Once in the classroom, the teacher and students concentrate their efforts on consolidating their understanding, putting ideas into practice and resolving new problems. When things are done this way, the students can really make the most of their interaction with the teacher.

\section{RESULTS}

Students enrolled in our course were also following an introductory course in computer graphics (an average of 25 students). This course has the exact same characteristics: 4.5 ECTS, elective course and in spring semester of the 4th year in the Degree in Computer Engineering. This fact allowed us to compare the perception of the students in front two different strategies: with and without flip teaching.

The computer graphics course classes are lecture-based, where the most part of the practical work must be done at home. ${ }^{12}$

A questionnaire was used to get students' appreciation of the flip teaching approach. Among other more general topics, two questions were focused on comparing the two teaching approaches of the two courses (the same set of students):

- Q1. Do you find flip teaching methodology with the MOOC better than the lecturebased approach?

- Q2. Do you think your final results and achievements will be better with this methodology?

The results of the questions were given using a Likert scale (1-Totally disagree to 5-Totally agree). The median form Q1 was 5, and for Q2 was 4. See Figure 2.

The final grades of the students were also compared in two different editions of the introductory course in game programming: without and with flip teaching. The students' grades were better with flip teaching (see Figure 2) and they were able to develop better and more complete games (see Figure 3).

Our results have been also considered in a broader analysis of flip classroom methodologies in our University. With more than 400, our University is the one with more lecturers having used flip teaching. Only last year, 270 lecturers taught 256 courses with this methodology. $87 \%$ of lecturers and $55 \%$ of the students consider this methodology as positive. ${ }^{13}$ 

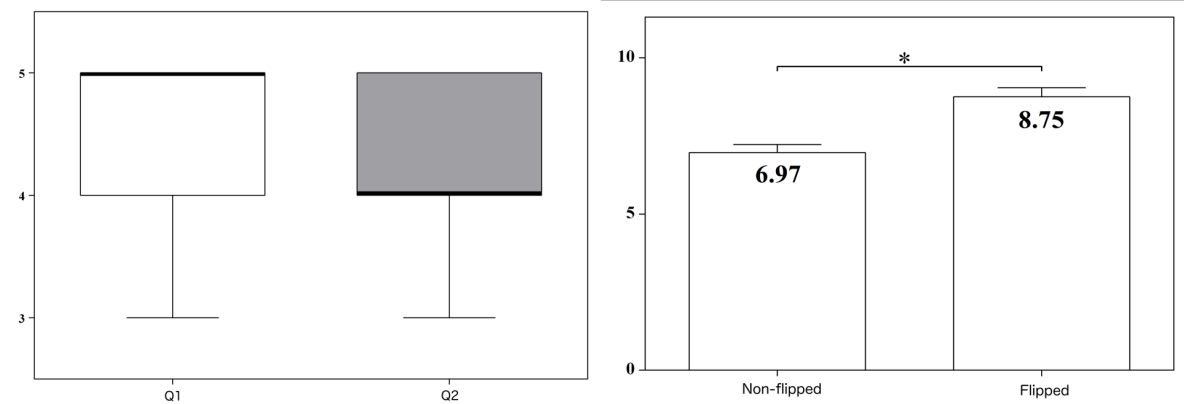

Figure 2. (Left) Students found flip teaching a better approach Q1 (median 5), and they thought they were able to get better results $\mathrm{Q} 2$ (median 4$)$, interquartile range 4-5 $\left(P_{25}-P_{75}\right)$. (Right) Student's grades without and with flip teaching (from 0 to 10). With flip teaching grades were significantly better, $t(27)=-3.09, p=0.005(p<0.05)$, t-Student, Shapiro-Wilk and Levene tests.
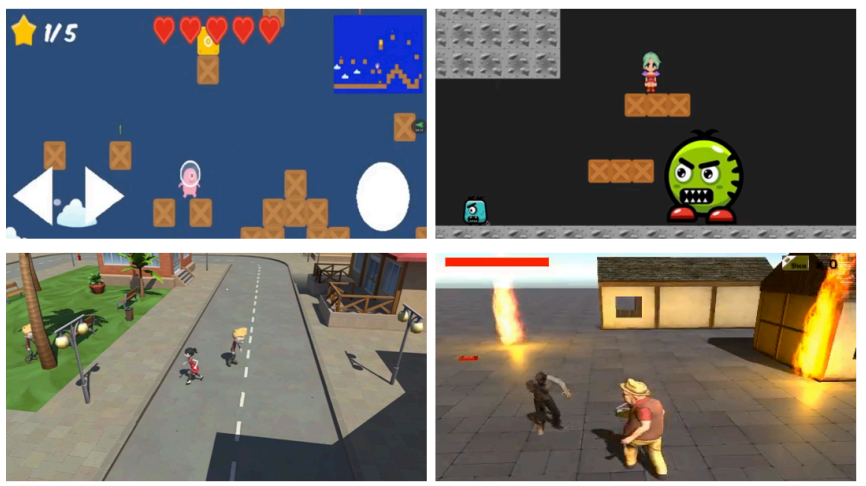

Figure 3. Some examples of games developed by students. Games were better and more complex that those of previous editions without flip teaching.

\section{CONCLUSION}

Flip teaching is rapidly becoming a methodology with many possibilities for current students. It has many advantages over lecture-based teaching systems, although it implies greater effort from both students and teachers.

In our case, we have had better results confirmed in two ways:

- Better results and grades in students' assessment.

- Using a satisfaction survey completed by the students, a preference for flip teaching with MOOCs was clearly demonstrated over the lecture-based method.

The new teaching materials and MOOCs are also ideal for use in a university environment. The use of these resources and the new methodologies such as flip teaching are particularly interesting for students of computer graphics and game development, as teachers and students will share their time in the classroom working on the higher levels of Bloom's taxonomy.

\section{REFERENCES}

1. J. Baker, "The classroom flip", Using web course management tools to become the guide on the side, 2000 
2. N. Sarawagi, "Flipping and introductory programming course: Yes you can!", $J$. Comput. Sci. Coll., vol. 28, pp. 186-188, June 2013.

3. V. Käfer, D. Kulesz, and S. Wagner, "What Is the Best Way For Developers to Learn New Software Tools?", The Art, Science, and Engineering of Programming, vol. 1, no. 2, 2017.

4. A. Hogue, B. Kapralos, and F. Desjardins, "The role of project-based learning in it: A case study in a game development and entrepreneurship program", Interactive Technology and Smart Education, vol. 8, no. 2, pp. 120-134, 2011.

5. J. Ryoo, F. Fonseca, and D. S. Janzen, "Teaching Object-Oriented Software Engineering through Problem-Based Learning in the Context of Game Design," 21st Conference on Software Engineering, Education and Training, pp. 137-144, 2008.

6. E. F. Anderson and C. E. Peters, "On the Provision of a Comprehensive Computer Graphics Education in the Context of Computer Games: An Activity-Led Instruction Approach,", 2009.

7. L. Pappano, "The year of the mooc", The New York Times, vol. 2, no. 12, 2012.

8. "Introducción al desarrollo de videojuegos con Unity." https://www.edx.org/es/course/introduccion-al-desarrollo-de-upvalenciax-uny201-x-1.

9. "MIT and Harvard edX platform." http://edx.org.

10. I.M. Despujol, C. Turro, J. Busqueis, and A. Canero, "Analysis of demographics and results of student's opinion survey of a large scale mooc deployment for the spanish speaking community," Proceedings -Frontiers in Education Conference, FIE, vol. 2015-Febru, no. February,2015

11. P. J. Guo, J. Kim, and R. Rubin, "How video production affects student engagement", Proceedings of the first ACM conference on Learning@scale conference-L@S '14, pp. 41-50, 2014

12. J. Linares-Pellicer, P. Micó, J. Esparza-Peidro, and E. Carrasquer-Moya, "Computer graphics: from desktop to mobile and web," IEEE computer graphics and applications, vol. 31, no. 4, pp. 94-96, 2011

13. "UPV. Flipped classroom report (2016-17)." http://docenciainversa.blogs.upv.es/files/2018/01/INFORME-DIN-PARA-WEB.pdf

\section{ABOUT THE AUTHORS}

Jordi Linares-Pellicer is a lecturer and researcher at Universitat Politècnica de València. His research interests are interactive technology and VR/AR. He is a IEEE member. Contact him at jlinares@dsic.upv.es.

Jorge Orta-Lopez is a lecturer and $\mathrm{PhD}$ candidate at Universitat Politècnica de València. His research interests are interactive technology and VR/AR in education. Contact him at jororlo2@upv.es.

Juan Izquierdo-Domenech is a $\mathrm{PhD}$ candidate at Universitat Politècnica de València. His research interests are interactive technology and VR/AR in industry. Contact him at juanjesusizquierdodomenech@gmail.com. 